\title{
BACK ANALYSIS OF THE 2014 SAN LEO LANDSLIDE USING COMBINED TERRESTRIAL LASER SCANNING AND 3D DISTINCT ELEMENT MODELLING
}

\author{
Margherita Cecilia Spreafico ${ }^{1}$, Mirko Francioni ${ }^{2}$, Federico Cervi ${ }^{1}$, Doug Stead ${ }^{2}$, Gabriele Bitelli ${ }^{1}$, Monica \\ Ghirotti $^{3}$, Valentina Alena Girelli ${ }^{1}$, Claudio Corrado Lucente ${ }^{4}$, Maria Alessandra Tini ${ }^{1}$ and Lisa Borgatti \\ ${ }^{1}$ Department of Civil, Chemical, Environmental and Materials Engineering DICAM, Alma Mater Studiorum \\ Università di Bologna, Viale del Risorgimento 2, 40136 Bologna, Italy \\ ${ }^{2}$ Department of Earth Sciences, Simon Fraser University, 8888 University Dr, V5A 1S6 Burnaby, BC, Canada \\ ${ }^{3}$ Department of Physics and Earth Sciences, University of Ferrara, Via Saragat 1, 44122 Ferrara, Italy \\ ${ }^{4}$ Regione Emilia-Romagna, Servizio Tecnico di Bacino Romagna, Via Rosaspina 7, 47923 Rimini, \\ Italy \\ Corresponding author: Monica Ghirotti (email: monica.ghirotti@unife.it)
}

\begin{abstract}
Landslides of the lateral spreading type, involving brittle geological units overlying ductile terrains, are a common occurrence in the sandstone and limestone plateaux of the northern Apennines of Italy. The edges of these plateaux are often the location of rapid landslide phenomena, such as rock slides, rock falls and topples. In this paper we present a back-analysis of a recent landslide (February 2014), involving the north-eastern sector of the San Leo rock slab (northern Apennines, Emilia-Romagna Region) which is a representative example of this type of phenomena. The aquifer hosted in the fractured slab, due to its relatively higher secondary permeability in comparison to the lower clayey units leads to the development of perennial and ephemeral springs at the contact between the two units. The related piping erosion phenomena, together with slope processes in the clayshales have led to the progressive undermining of the slab, eventually predisposing large-scale landslides. Stability analyses were conducted coupling Terrestrial Laser Scanning (TLS) and Distinct Element Methods (DEMs). TLS point clouds were analyzed to determine the pre- and post-failure geometry, the extension of the detachment area and the joint network characteristics. The block dimensions in the landslide deposit were mapped and used to infer the spacing of the discontinuities for insertion into the numerical model. Threedimensional distinct element simulations were conducted, with and without undermining of the rock slab. The analyses allowed an assessment of the role of the undermining, together with the presence of an almost vertical joint set, striking sub-parallel to the cliff orientation, on the development of the slope instability processes. Based on the TLS and on the numerical simulation results, an interpretation of the landslide mechanism is proposed.
\end{abstract}

KEYWORDS: Rock slide-rock topple; Terrestrial Laser Scanner, 3D Distinct Element Method, Discontinuity sets, Undermining

\section{Introduction}

Deep Seated Gravitational Slope Deformations (DSGSDs) have been discussed by numerous Authors (Dramis and Sorriso-Valvo 1994; Varnes 1978; Crosta 2006; Martinotti et al. 2011). Two main types of DSGSD are described in literature, namely sackungen and lateral spreading phenomena. The latter are defined as lateral expansion of rock masses occurring along shear or tensile fractures with displacement along an undefined basal shear surface. Despite their slow velocity, these phenomena may predispose or trigger collateral faster landslides such as falls, topples, slides and flows (Soldati 2013). The observed mechanism depends on both the local geological and structural setting and on the geodynamical evolution of the area (Bozzano et al. 2013). Lateral spreading landslides are very common in the northern Apennines, where brittle limestone and sandstone slabs overlie softer clay-rich substrata. The process is often driven by deformation within the underlying material and generally induces horizontal spreading and progressive break-up of the rock mass. In some cases, the spreading can evolve into the complete fragmentation of the slab (Conti and Tosatti 1996). Examples of this process can be recognized, for example, in the Maltese archipelago (Mantovani et al. 2013) and at Cinque Torri (Eastern Alps, Italy, Viero et al. 2010). The phenomena have been widely studied by several Authors. Casagli (1994) and D'Ambra et al. (2004) used numerical models to show how the deformability contrast between the brittle and the ductile units leads to the development of a complex stress state within the rock slab. This stress can cause the gradual opening of the fractures striking parallel to the cliffs. Pasuto and Soldati (2013) indicated the overburden weight of the slab as a common cause for long-term deformations in softer terrains. Lateral erosion 
and removal of the clayey substratum, e.g. caused by erosion, were also suggested as a triggering factor. Bozzano et al. (2008) investigated the geological evolution of the Orvieto slab using a stress-strain analysis. The numerical simulations demonstrated that the deformation was driven by stress reduction in the tuff plate. Moreover, the evolution of the phenomenon can be also related to the presence of a well-developed system of fractures within the rock mass (Pasuto and Soldati 2013), which can result in a higher secondary permeability (Cervi et al. 2014). Due to the almost-impermeable clay-rich substratum, an aquifer can develop inside the rock mass and eventually play an important role in the stability of the slopes (Spreafico et al. 2015 a). Perennial and ephemeral springs discharging at the contact between the rock mass slab and the clay-shales can cause accelerated erosion and remoulding of the softer materials, leading also to the triggering of flow-like landslides. These processes together lead to the progressive undermining of the slab, which can accelerate the onset of collateral landslides at the edges of the plateaux. Evans (1981), in fact, noted that undercutting at the slope toe and the weathering of the basal material produce secondary toppling phenomena in vertical cliffs.

The San Leo landslide, which occurred on the 27th of February 2014, provides further insight for the understanding of these mechanisms, resulting in local rapid landslides in the context of lateral spreading phenomena. Due to this landslide, the medieval town, built on the top of a calcarenite slab, was seriously threatened by the retrogression of the scarp. The 2014 failure involved a large volume of rock but is only the latest of a number of similar events which affected San Leo over historical time. In this paper, we investigate the role of discontinuities and undermining at the base of the cliff on the deformation of the slab through geomechanical modelling. Terrestrial Laser Scanner (TLS) surveys and 3D Distinct Element Methods (DEMs) have been coupled to provide an improved understanding of the triggering mechanism of the 2014 landslide. Many authors have demonstrated the use of TLS for describing the topography and the structural setting of rock cliffs (Sturzenegger and Stead 2009 a, b; Fekete and Diederichs 2013; Francioni et al. 2014). Distinct Element Methods have been widely used to simulate rock slope failure involving joint controlled displacements (Brideau and Stead 2010; Kalenchuk et al. 2010; Brideau et al. 2011; Sturzenegger 2011).

LiDAR surveys were carried out before and after the February 2014 failure, allowing definition of the pre- and post-failure geometries of the slope, the 3D topography, the discontinuities characteristics and the block dimensions. Data extracted from the TLS point clouds and from traditional geomechanical surveys were used for developing a 3D numerical model. The 3DEC code (Itasca ${ }^{\mathrm{TM}} 2008$ ) was used for the rock slope stability simulations. Based on the results an interpretation of the landslide mechanism is proposed.

\section{Case Study: the San Leo Rock Spreading}

\subsection{Cultural Heritage}

The town of San Leo is well-known for its historical and cultural relevance. The first settlement dates back to the III century B.C. when the Ancient Romans constructed the Jupiter temple and a fortification on the highest part of the slab. Between 962 and 964 A.D. it became the last capital of the Italic Longobardic Empire of Berengario II, after his defeat in Pavia. Several intellectual and religious historical figures lived in the town, such as Dante Alighieri, S. Francesco d'Assisi and San Leone; the latter gave his name to the town. The medieval castle, situated on the south-eastern side of the slab overlooking the Marecchia Valley, was the location of important battles during the Renaissance period. Later, under the Papal States, San Leo became the location of a prison, where the Count of Cagliostro, a famous occultist, and Felice Orsini, an Italian revolutionary who tried to assassinate Napoleon III, were imprisoned. Other noteworthy buildings are located in the historical centre of San Leo including the parish church, the cathedral and the bell tower. The San Leo cliffs have been affected by several slope instability phenomena over the centuries: the access to the town has been moved several times after being destroyed by rock falls.

\subsection{Geological and Geomorphological Setting}

The San Leo rock slab is located in the northern Apennines (Fig. 1), at about $590 \mathrm{~m}$ a.s.l. The main geological units outcropping in the area belong to the Ligurian and Epiligurian domains. The Ligurian units were deposited, between the Cretaceous and Middle Eocene, in a deep marine environment and subsequently overthrusted the autoctonous Umbro-Marchean-Romagnan units. They are mainly composed of clayey, silty and marly materials. The overthrusting led to intense deformation of the Ligurian deposits, resulting in the development of highly fissured and overconsolidated clay-shales.

The Ligurian units are unconformably overlain by sedimentary deposits, known as the Epiligurian units, which were deposited during the Middle-Late Eocene and the Late Messinian in the minor piggy-back basins developed on the Ligurian units during their translation, and were transported to their current position. Usually, they comprise limestones and sandstones. Differential weathering and erosion processes have resulted in these rock slabs being clearly recognizable within the gentle clayey slopes (Fig. 2). 

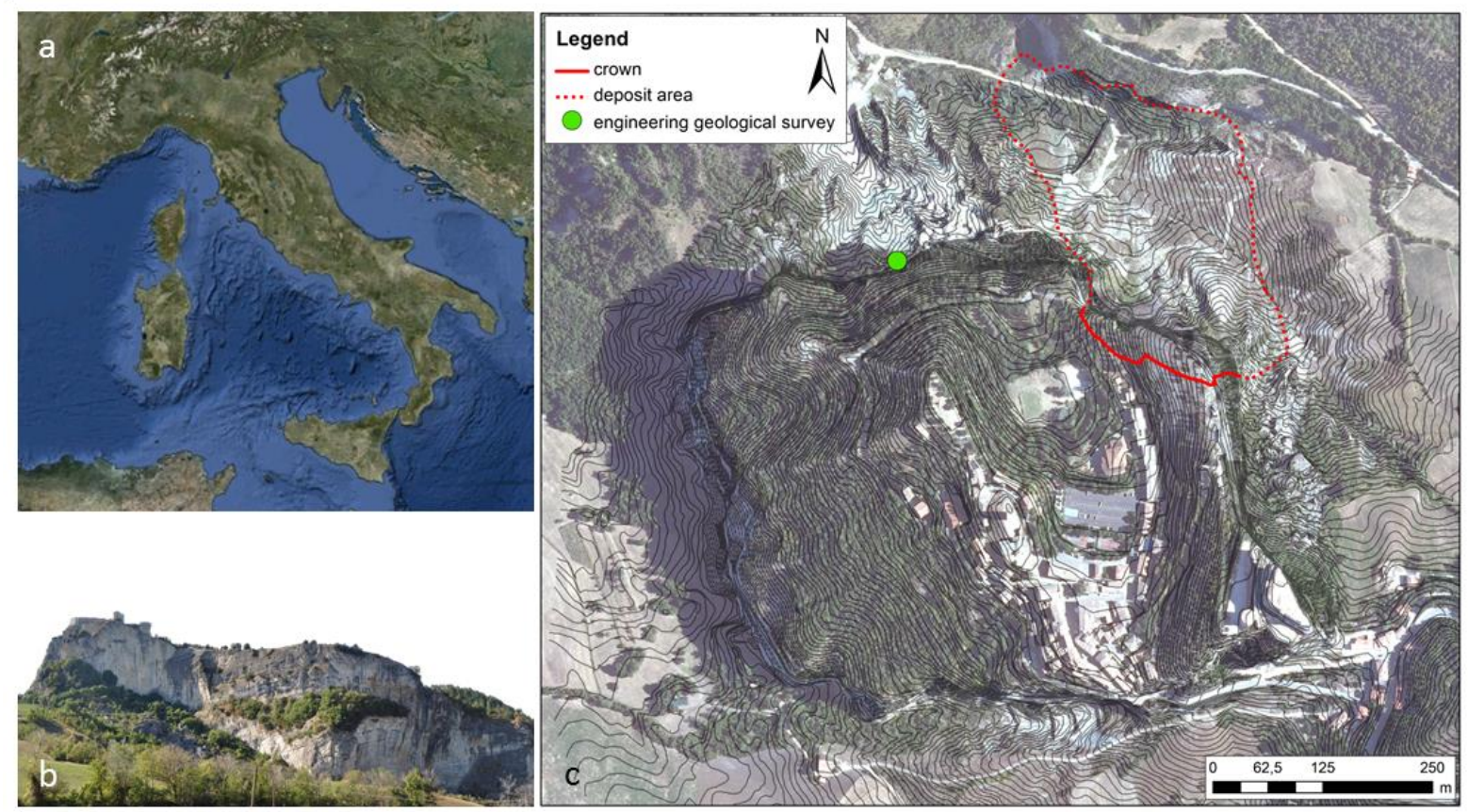

Fig.1 San Leo rock slab, a) geographical setting, b) east cliff in 2012 and c) aerial orthophoto (2007), the red lines indicate the area of the 2014 landslide, the green point indicates the area in which the engineering geological survey was undertaken

In the San Leo area, the Ligurian units are represented by the so-called Argille Varicolori clay-shales, a tectonically disrupted unit (CARG project 2013). The rock slab is formed by the Monte Fumaiolo sandstones and the San Marino limestones. It is about $600 \mathrm{~m}$ long EW and $500 \mathrm{~m} \mathrm{NS}$, with a general south-westward dipping. The cliffs that border the plateau are sub-vertical or overhanging, and are up to $100 \mathrm{~m}$ high in the eastern side of the slab. The rock mass is highly fractured due to a number of discontinuity sets and faults.

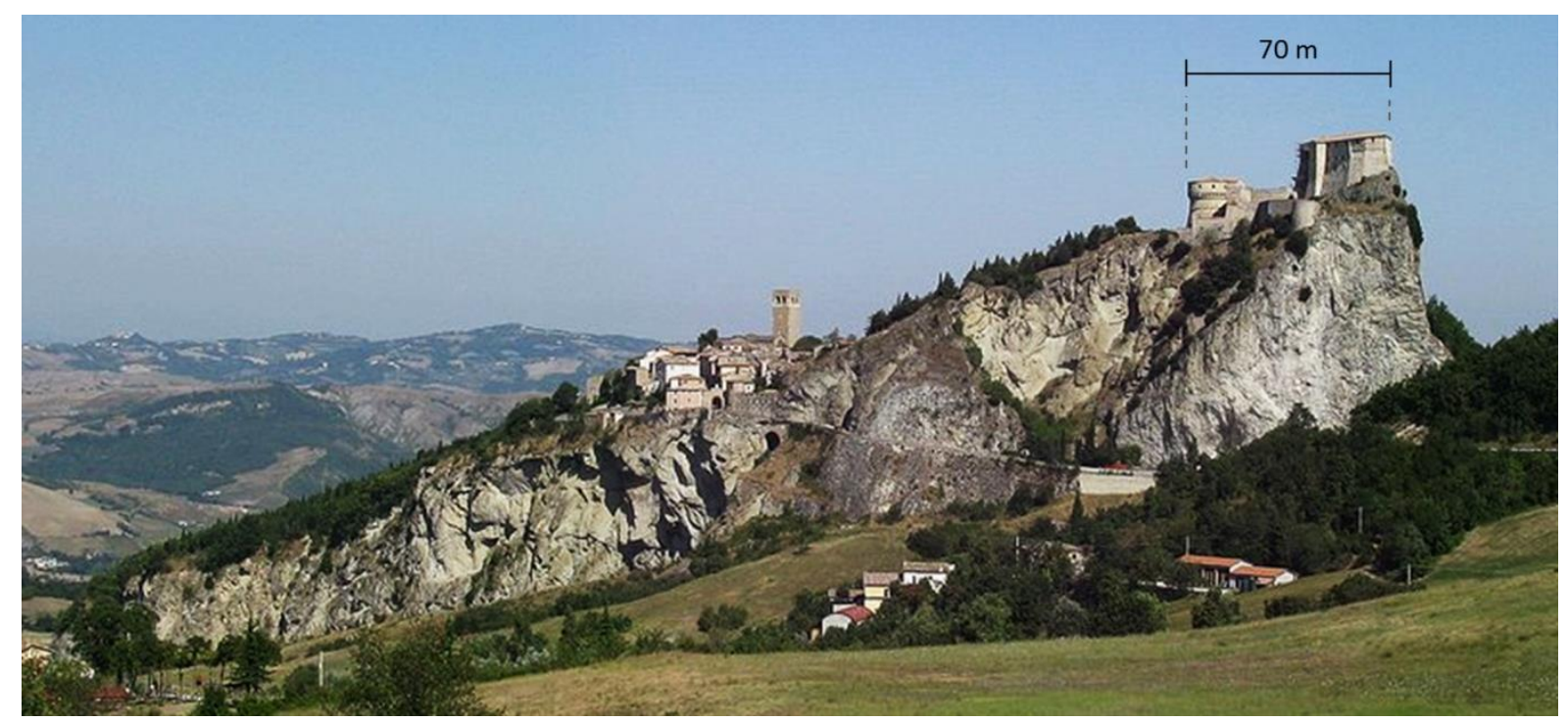

Fig.2 San Leo rock slab, view of the south cliff. Scale is indicative

\subsection{Typical Slope Instability Phenomena}

Slope instability processes affect both the rocky slab and the surrounding clay-shale units. As mentioned in the introduction, the overall slope deformation can be described as a lateral spread involving the brittle rock slab overlying a more ductile terrain. The slab is also affected by rock falls and topples, occurring at its edge, while the clay-shale substratum is involved in slower movements, including earth slides, earth flows and creep. The slope processes occurring within the different units are correlated. The water infiltration in the fractured slab leads to the formation of ephemeral and perennial springs at the contact between the two units. Piping erosion 
processes and progressive remoulding, together with minor landsliding, led to the removal of the clay-rich material at the toe of the slab. The cliff subsequently becomes unstable due to undermining. The subsequent topple or fall may cause an undrained loading on the substratum, which in turn leads to the reactivation or to the acceleration of the slope movements involving the clay-shale units. Moreover, the stress developing before the rock failure may contribute to the formation of discontinuities within the rock slab. Analysing the phenomena at the cliff-scale, although the lateral spread can definitely influence the acting processes, the undermining at the toe of the cliff seems to play a key-role in ultimate failure developing. Slope instability processes affecting the San Leo rock slab are apparent in ancient photographs, drawings and writings covering the last 4 centuries (Benedetti et al. 2013). In the last decade, two large-scale failures have occurred. The first, on the $11^{\text {th }}$ May 2006, affected the northern side of the slab (Fig. 1c). A rock fall, suddenly detached from the vertical cliff, resulting in undrained loading at the top of the clay-shale slope triggering an earthflow that reached velocities in the order of $4.2 \mathrm{~cm} / \mathrm{h}$. The last landslide occurred on the $27^{\text {th }}$ February 2014 and is analysed in the present work. The most recent landslide is described by Borgatti et al. (2015, see Fig. 3).
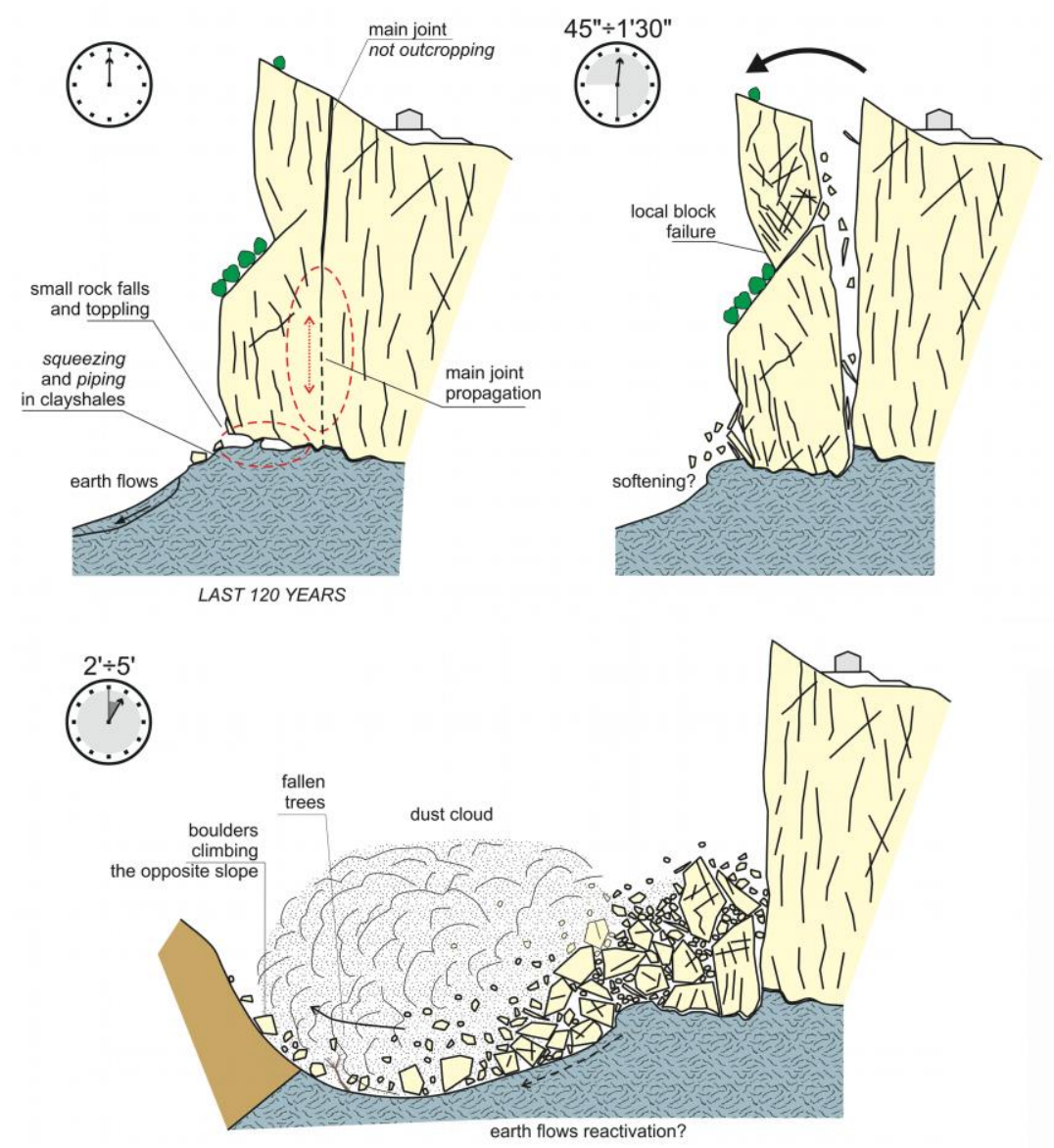

Fig. 32014 San Leo landslide. Clocks highlights the time sequence of the event, based on the reports of witnesses and on the seismic record (modified after Borgatti et al. 2015)

The 2014 landslide took place on the north-eastern side of the slab, in an area strongly affected by the erosion and undermining at the slope toe. The volume of the landslide has been estimated at about $300.000 \mathrm{~m}^{3}$ (Spreafico et al. 2014). After the failure, a marked surface could be observed at the top of the slope (Fig. 4). This fracture, referred to as SL2.1, was recognized as the plane along which part of the failure took place. Considering the degree of alteration of the rock surface, probably due to aperture and water circulation, it is suggested that the discontinuity was pre-existing. In particular, discontinuities belonging to the same set were mapped on the top of the slab, having a mean spacing of 20-22 m (Enser, 2014). The retreat of the cliff scarp endangered a road, several private buildings, a police station and a school. 


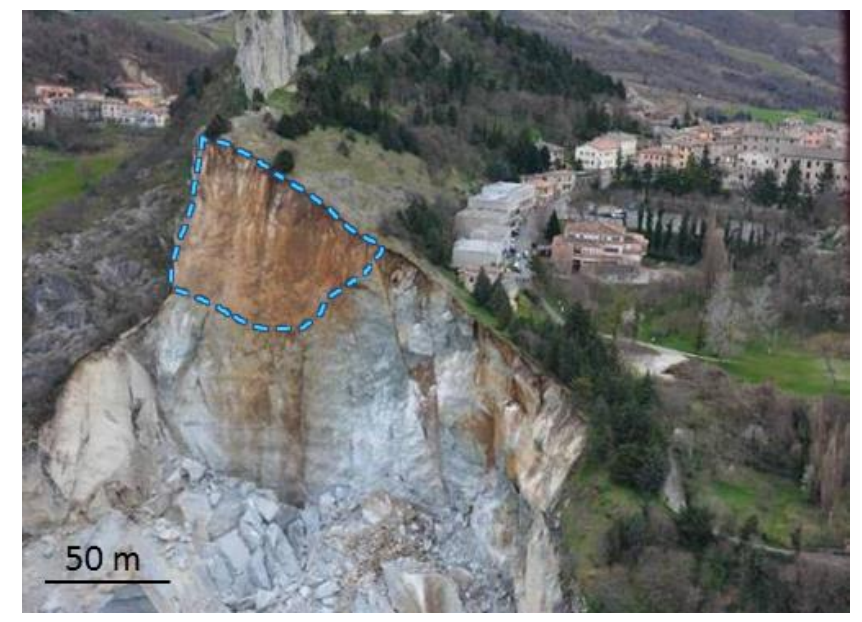

Fig. 4 View of the landslide area from the top, the dashed blue line highlights the discontinuities named SL2.1.

Scale is indicative (Photo courtesy STB Romagna)

\section{Material and Methods}

Terrestrial Laser Scanning (TLS), and numerical modelling using Distinct Element Methods (DEMs) were combined in the back-analysis of the 2014 rock-slope failure. Field work and TLS surveys were used to determine the input parameters for the 3D numerical model. The TLS surveys, taken before and after the failure, allowed the pre- and post-failure geometry of the slope to be defined. The pre-failure topography was inserted directly into the 3DEC models and a comparison between the two surfaces was used to constrain the simulation results. Analysis of TLS point clouds provided the geometrical parameters of the joint systems (orientation, persistence, mean trace length) for input into the DEM models. The spacing between discontinuities was derived by measuring the dimension of the fallen blocks directly on the TLS point cloud. The mechanical properties of the joint sets were calculated based on data from traditional geomechanical surveys. A flowchart summarizing the adopted workflow is illustrated in Fig. 5.

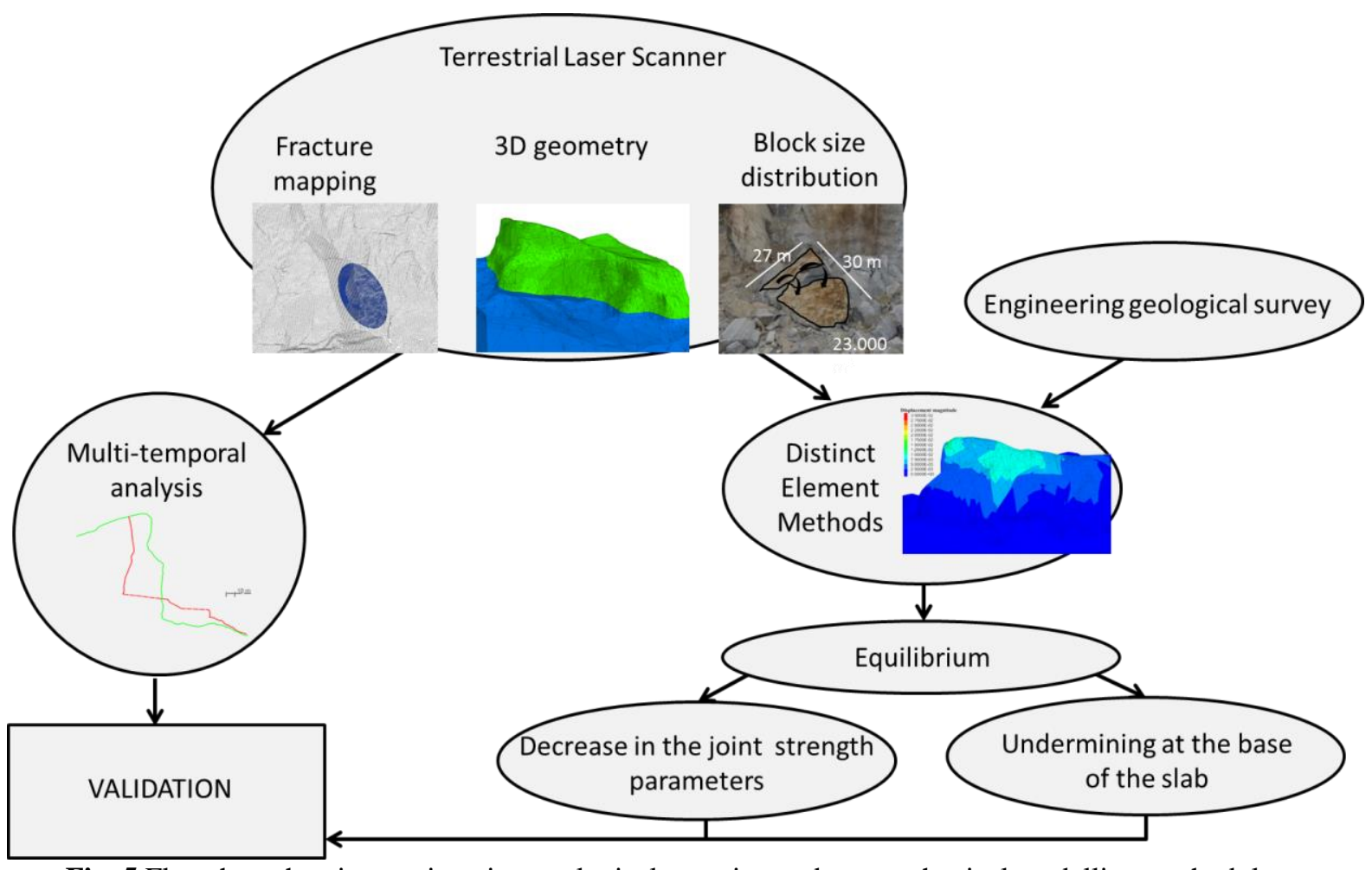

Fig. 5 Flowchart showing engineering geological mapping and geomechanical modelling methodology

Under-mining, Analysis; decrease in the 


\subsection{Engineering Geological Survey}

Traditional geomechanical surveys were used to statistically define the discontinuity sets and to assess the mechanical properties of each set. Furthermore, they were used to validate the TLS results. The survey was undertaken in the proximity of the 2014 landslide (Fig. 1) using scan-line methods according to the International Society for Rock Mechanics (ISRM, 1985). Several parameters such as orientation, spacing, roughness, aperture and infilling of the discontinuities were collected. The Joint Roughness Coefficient (JRC, Barton and Choubey 1977) and the Joint Compression Strength (JCS, Deere and Miller 1966) were also measured. Using the JRC and JCS values it was possible to estimate the values of cohesion and friction angle for each joint set by fitting the non-linear Barton Bandis strength envelope to the Mohr Coulomb envelope. For this purpose, the basal friction angle was assumed to be equal to 29 degrees, based on previous measurements. The fitting procedure was performed over a specific stress range based on the slope height (approximately $100 \mathrm{~m}$ ) and the unit weight of the material $\left(26 \mathrm{kN} / \mathrm{m}^{3}\right)$.

\subsection{Terrestrial Laser Scanner Survey}

\subsubsection{TLS acquisition}

A series of TLS scans were taken between 2008 and 2011 with a Rieg1420i system. The survey covered both the northern and eastern cliffs (Spreafico et al. $2015 \mathrm{~b}$ ). The scanning of the remaining southern and western cliffs was completed by the authors in 2013 using a Riegl VZ400 system coupled with a calibrated digital camera. The scans of the 2013 surveys were joined with the ones derived from the previous surveys (2008-2011), permitting to obtain a complete model of the cliffs. The registration of the point clouds was carried out both defining manual tie points on the scans and using total station and GPS surveys to georeference all the point cloud in the WGS84 reference system. Due to the complexity of putting together point clouds of different surveys, it is difficult to attribute an overall quality index to the whole model; however, a centimetre accuracy can be considered. The complete point cloud model is composed of about 618 million of points. After the 27th February 2014 detachment, the TLS survey was repeated in the area affected by the failure using Riegl VZ400 equipment. This survey was conducted in the 6th March 2014 from two scan positions, acquiring the detachment surface with a resolution of about $5 \mathrm{~cm}$ (Fig. 6).

The point clouds registration was performed using tie points in the form of 6 purpose-built polystyrene spheres with $30 \mathrm{~cm}$ diameter. During the laser scanning survey, the spheres were sampled using very high density point cloud.

In order to obtain the 3D position of the centre of the spheres in the WGS84 reference system a GNSS fast static survey was conducted. Therefore, after the scanning operation, each sphere was replaced with the GNSS antenna. Knowing the mutual difference in height between the centre of the sphere and the GPS antenna, it was possible to obtain the WGS84 coordinates of each sphere centre. The 3D WGS84 positions were then projected in the cartographic system UTM-WGS84 (zone 33).

After the GNSS and laser scanner data post processing the overall accuracy of the point cloud is sub-centimetre in terms of relative positioning and at the centimetre level in terms of absolute orientation.

The coloured point cloud (RGB information obtained from the calibrated digital camera set up on the laser scanner) comprises more than 53 million points oriented in the UTM-WGS84 cartographic system.

a

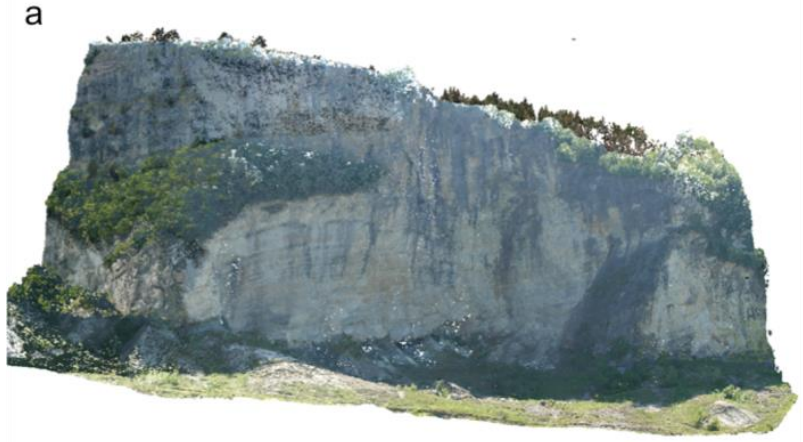

b

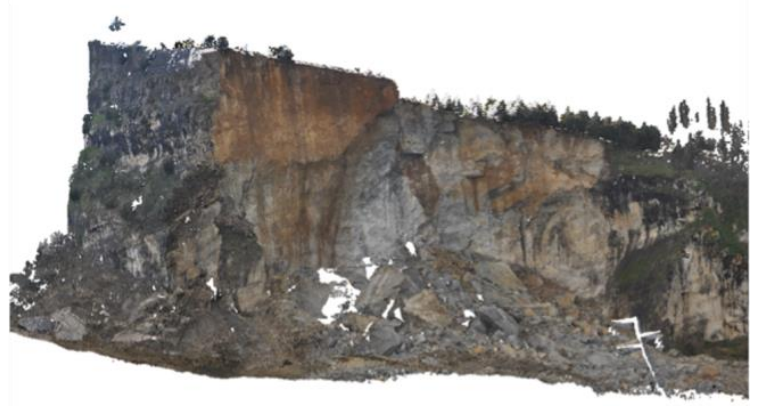

Fig. 6 TLS point clouds, pre- (a) and post-failure (b) 
Due to the extensive area of the outcrop, the danger for the operators and the difficulties encountered accessing the majority of the slab perimeter, only small sectors at the base of the cliffs could be surveyed using traditional methods. The extraction of the main discontinuities was therefore performed directly on the 3D point clouds, using the Polyworks (Innovmetric Software, 2014) software. Discontinuity window mapping was undertaken according to the procedure suggested by Sturzenegger et al. (2011): three circular windows with a radius equal to $20 \mathrm{~m}$ were selected for each point cloud (pre- and post-failure). Mauldon et al. (2001) noted that the use of circular windows can eliminate the sampling bias along mapped surfaces. The windows were located on exposures with different orientation, to reduce the orientation bias occurring in the third dimension. During the mapping procedure fractures were assumed to be planar and circular. A manual procedure was adopted, fitting the recognizable discontinuities with circles. Dip and dip direction were obtained from the direction cosines of the normals to the circles representing the discontinuities, allowing the definition of the main joint sets. The survey results were validated by comparison with the results of the geomechanical surveys described in the present paper. Moreover, by averaging the diameters of the mapped discontinuities a mean trace length value was obtained for each joint set (Sturzenegger and Stead, 2009 a). The joint persistence was estimated as the length of fracture traces per unit area of sampling surfaces $\left(\mathrm{P}_{21}\right.$, as defined in Dershowitz et al. 1998). An initial attempt to evaluate the stability of the cliff was performed using kinematic analyses.

\subsubsection{Block Size Distribution}

Block size dimensions were estimated by inspecting the TLS point cloud of the deposit area. The main purpose of the analysis was the evaluation of the effective mean spacing between discontinuities bordering the blocks. The procedures illustrated by Shugar and Clague (2011) for aerial photogrammetry mapping was adapted to calculate the block dimensions from the TLS point cloud. For each block, the visible surfaces were fitted by rectangles. The length and width of the rectangles were subsequently measured. Often, it was not possible to measure all the block surfaces. Indeed, depending on the TLS position during data acquisition, some blocks were not visible in the TLS line of sight, while others were partially obscured by debris. For all the inspected blocks, at least one surface was measured (2 dimensions). Where possible, the third dimension was also collected. In the remaining cases, the third dimension was estimated as the average value of the other two. The volume and the average side length of the blocks were finally calculated.

\subsubsection{Multi-temporal Analysis}

A comparison between multi-temporal TLS data has been demonstrated to be useful for monitoring slope displacements and deformation (Abellan et al. 2011), to delineate their extent, to estimate the involved volume (Kuhn and Prüfer 2014) and to provide a general description of the ongoing processes (Pesci et al. 2007).

As stated before, two point clouds of the landslide area were available, before and after the event. At first a 2D change detection analysis was performed by comparing sections extracted directly from the point clouds. With the aim to perform a 3D comparison and to delineate the landslide extent, a polygonal model was generated from the point clouds. The deviation of the pre-landslide surface from the post-landslide surface was measured along the north direction, almost perpendicular to the cliff face, using a specific tool available in the Polyworks IMsurvey module (Innovmetric 2014). The difference between the two surfaces was then calculated and projected onto the post-failure surface.

\subsection{Back Analysis Using 3D Distinct Element Modelling}

In order to analyze the 2014 landslide, the three dimensional distinct element code 3DEC (Itasca ${ }^{\mathrm{TM}} 2014$ ) was used. This software has been successfully applied to landslide modelling by several authors as it allows representation of the full 3D geometry and the incorporation of discontinuities (Stead et al. 2006; Yeung and Wong 2007; Brideau and Stead 2010; Kalenchuk 2010; Brideau and Stead 2011; Firpo et al. 2011; Brideau and Stead 2012). An explicit time marching solution is used to simulate the response of discontinuous rock mass subjected to static or dynamic loading. Discontinuities are treated as boundary conditions between blocks, which can be considered either rigid or deformable. Different constitutive criteria can be used for blocks and for discontinuities. Large displacements along discontinuities are permitted in both the normal and shear direction. Moreover, excavation and backfill simulations can be easily performed using the "null" block procedure.

Based on field evidence, particular emphasis was given to the role of the recognized joint sets and of the undermining at the base of the slab.

Several assumptions were made:

- due to the geometrical complexity of the model, the blocks were considered to be rigid;

- the discontinuity systems were described using the mean spacing, the persistence and a constant orientation of the joint sets;

- groundwater was not accounted for.

The 3D pre-landslide point cloud was joined with the $1 * 1$ DTM of the area derived from photogrammetric aerial 
surveys. This allowed the complete topography to be described, i.e. both the sub-vertical cliff and sub-horizontal top of the slab. The 3D model was firstly created using the Delaunay triangulation in the CloudCompare (Girardeau-Montaut 2014) software. A resampling of the resolution at about $50 \mathrm{~cm}$ was used as an acceptable compromise between a precise description of the topography and a complexity that still permitted practical computer runtimes. The 3D model was imported into the Rhinoceros SR ${ }^{4}$ (McNeel and associates 2014) software to improve and correct the triangulated mesh. Finally the Kubrix mesh generator (Itasca ${ }^{\mathrm{TM}} 2014$ ) allowed a suitable model for the 3DEC code to be created. The contact between the rock slab and the substratum was created directly in the 3DEC environment and was derived from the interpolation of the data collected in 5 boreholes which were drilled between 1972 and 2001 (Fondedile Italsonda 1972; Geoemme 2001). All the boreholes were drilled almost vertically and no discontinuity measurements were performed.

The discontinuity orientations obtained from the TLS point clouds were grouped statistically into 3 main joint sets (SL1, SL2, and SL3), to be inserted in the model. In the 3DEC software, persistence factor is defined as the probability that any given block lying in the joint path is cut by a discontinuity. On the basis of the field evidence, e.g. the clearly visible discontinuity surface (SL2.1), a persistence factor equal to 1 was assigned to joint set SL2, and 0.5 to the other two sets (SL1, SL3). The assumed spacing value in the numerical simulations depends on the scale of the analysis, i.e. the extent of the study area. In intensively fractured rock masses, the spacing between discontinuities can be very low. The input of these spacing values in the numerical simulations can sometimes represent a problem if the area affected by deformation is large in extent in comparison with the area represented in the point cloud. Moreover, the spacing obtained from slope face surveys may be not representative of the situation within the interior of the rock mass (Francioni et al. 2014). In the San Leo cliffs the surveyed spacing is low and the 3 joint sets were detected even at a small scale. The blocks in the deposit area have a larger dimension than expected in comparison to the joint spacing determined from the field survey. It is clear that not all the discontinuities have an active role in the failure process and that rock bridges both on the surface and between joints play a key role in slope failure. In order to consider only the fractures actively involved in the slope failure mechanism, the spacing was assumed on the basis of the average post-failure block dimensions. This is suggested to provide a more realistic representation of the failure mechanism. The relative spacing between joints was maintained, i.e. the spacing values obtained from the survey were multiplied by the same factor (approximately 10), not to modify the rock mass behaviour. A deterministic approach was used for the insertion of joints belonging to the system SL2, matching their position in the model with that surveyed in the field and visible in the TLS point cloud. Boundary and initial conditions were applied by prescribing zero displacement along the boundary of the model and a gravity load to the entire model. The density of the rigid blocks was assumed to be $26 \mathrm{kN} / \mathrm{m}^{3}$ for the rock slab and $21 \mathrm{kN} / \mathrm{m}^{3}$ for the blocks representing the clayey substratum (Ribacchi and Tommasi, 1988). A Mohr-Coulomb constitutive criterion was assumed for the discontinuities. Cohesion and friction angle were derived from the results of the geomechanical survey and are in the range of values reported in the published literature (Barton, 1974; Hoek and Bray, 1981). The joint tensile strength was assumed equal to zero. The normal and shear stiffness were derived from the measured JRC and JCS parameters, applying the formulae reported in Barton and Choubey (1977). A mean spacing of $5 \mathrm{~m}$ and an average joint aperture equal to $1 \mathrm{~mm}$ were used, based on the results of the geomechanical and block dimensions surveys. The normal stress acting on a fracture was assumed to be in the order of $1 \mathrm{MPa}$. The initial values used in the simulations are reported in Table 1.

Table 1. Mechanical properties of discontinuities assumed in 3DEC analyses

\begin{tabular}{ccccc}
\hline Joint set ID & $\begin{array}{c}\text { Cohesion } \\
{[\mathbf{k P a}]}\end{array}$ & $\begin{array}{c}\text { Friction } \\
{\left[{ }^{\circ}\right]}\end{array}$ & $\begin{array}{c}\text { Kn } \\
{[\mathbf{M P a} / \mathbf{m}]}\end{array}$ & $\begin{array}{c}\text { Ks } \\
{[\mathbf{M P a} / \mathbf{m}]}\end{array}$ \\
\hline SL1 & 29 & 34.7 & 9500 & 950 \\
SL2 & 30 & 34.7 & 9500 & 950 \\
SL3 & 31 & 34.9 & 9500 & 950 \\
\hline
\end{tabular}

3DEC models were first run to equilibrium; then, two different scenarios were simulated. In the first case, the joint parameters were modified lowering the cohesion of the discontinuities by one order of magnitude to account for the degradation of joint properties. In the second case, the observed undermining at the base of the rock cliff was simulated. The extent of the undermined area on the border of the slab was based on field surveys and analysis of photos and TLS point clouds taken before the 2014 landslide (Fig. 7). The extent of the undermined area below the rock mass was estimated to be $20 \mathrm{~m}$. The reliability of the simulation results was assessed by comparing them with the data from the TLS multi-temporal analysis. In particular, the difference between the pre- and post-failure point clouds, showing the extent of the area affected by slope instability phenomena, and the contours of the failure main scarp were used to constrain the 3DEC simulation results. 

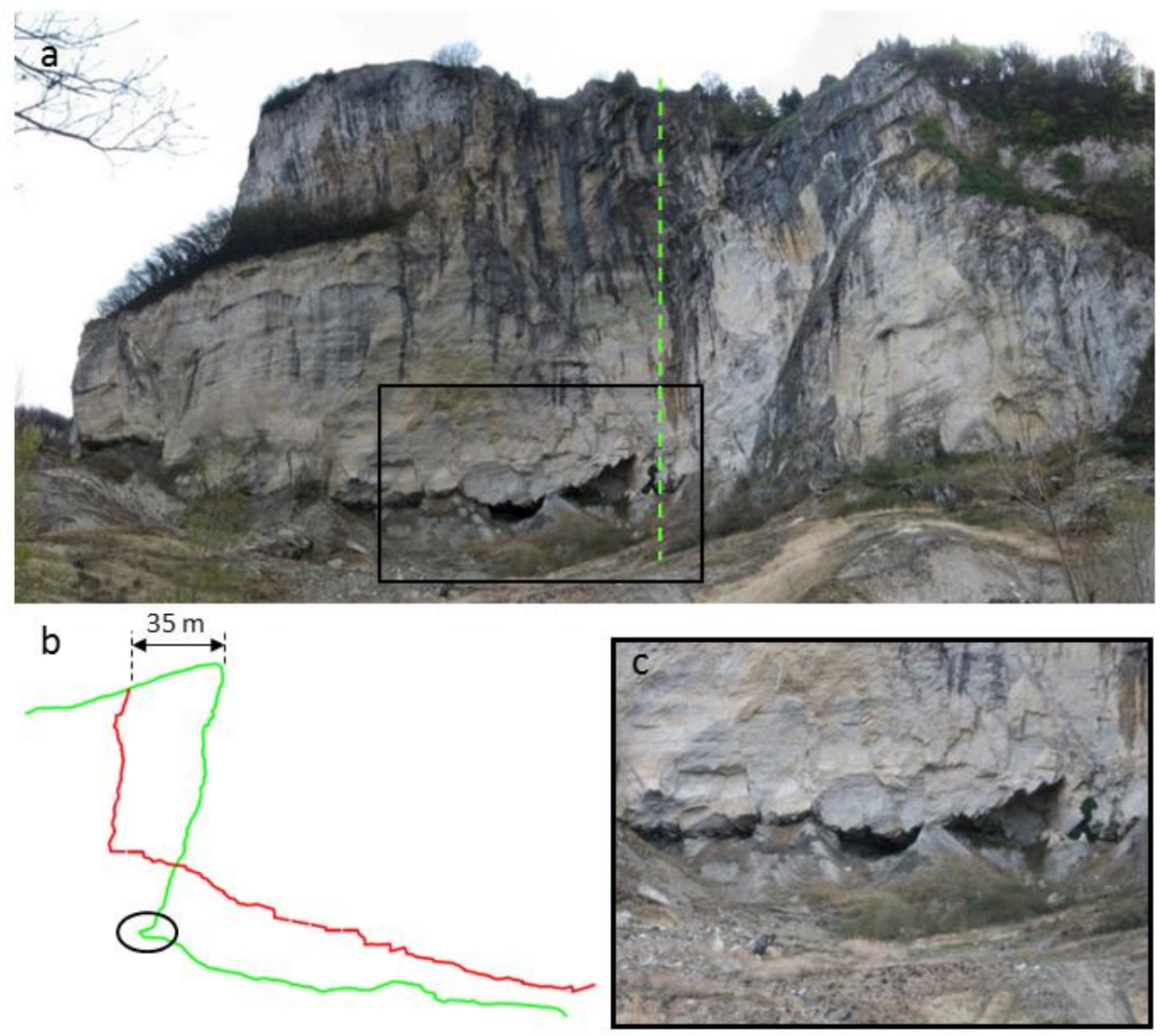

Fig.7 Undermining at the base of the cliff. Section 3 from TLS (b), in green the pre-failure surface with the undermined area highlighted in the black circle, and the post-failure surface shown in red. Photo of the area affected by the failure (pre-landslide): north-eastern cliff (a), and particular (c)

\section{Results}

\subsection{Engineering Geological Survey}

Results of the field surveys were statistically grouped into 3 discontinuity sets; which are shown in Table 2. All the sets showed similar values of JRC and JCS. It is noticeable that the joint set SL2 has a mean spacing almost 4 times greater than the SL1 and SL3.

Table 2. Joint properties derived from engineering geological surveys

\begin{tabular}{|c|c|c|c|c|c|c|c|}
\hline $\begin{array}{c}\text { Joint set } \\
\text { ID }\end{array}$ & $\begin{array}{c}\text { Dip } \\
{\left[^{\circ}\right]}\end{array}$ & $\begin{array}{c}\text { Dip } \\
\text { direction } \\
{\left[{ }^{\circ}\right]}\end{array}$ & Mean JRC & Mean JCS & $\begin{array}{c}\text { Mean } \\
\text { aperture } \\
{[\mathrm{mm}]}\end{array}$ & Infilling & $\begin{array}{c}\text { Mean } \\
\text { Spacing } \\
{[\mathrm{m}]}\end{array}$ \\
\hline SL1 & 65 & 272 & 8.6 & 40.3 & 1.7 & yes & 0.5 \\
\hline SL2 & 75 & 025 & 9.0 & 38.3 & 0.01 & no & 1.9 \\
\hline SL3 & 67 & 067 & 10.0 & 39.7 & 0.8 & yes & 0.7 \\
\hline
\end{tabular}

\subsection{TLS}

The results of the fracture mapping from TLS are shown in Table 3 and in Fig. 8. The main joint sets are identified in addition to the bedding planes which have an average orientation of $25^{\circ} / 230^{\circ}$. Comparing the data before and after the landslide an increase in the joint intensity after the failure appears $\left(\mathrm{P}_{21}\right.$ in Table 3$)$.

Table 3. Joint properties derived from the TLS point clouds. $\mathrm{P}_{21}$ is defined in Dershowitz et al. (1998). MTL refers to the joint Mean Trace Length 


\begin{tabular}{ccccccc}
\hline Joint set ID & $\begin{array}{c}\text { Dip } \\
\left.{ }^{\circ}\right]\end{array}$ & $\begin{array}{c}\text { Dip } \\
\text { direction } \\
{\left[{ }^{\circ}\right]}\end{array}$ & $\begin{array}{c}\mathbf{P}_{21} \text { pre } \\
\text { landslide }\end{array}$ & $\begin{array}{c}\mathbf{P}_{21} \text { post } \\
\text { landslide }\end{array}$ & $\begin{array}{c}\text { MTL pre } \\
\text { landslide } \\
{[\mathbf{m}]}\end{array}$ & $\begin{array}{c}\text { MTL post } \\
\text { landslide } \\
{[\mathbf{m}]}\end{array}$ \\
\hline SL1 & 79 & 239 & 0.10 & 0.14 & 6.9 & 9.8 \\
SL2 & 84 & 023 & 0.08 & 0.09 & 4.4 & 7.8 \\
SL3 & 59 & 043 & 0.11 & 0.11 & 7.6 & 5.8 \\
\hline
\end{tabular}

For the kinematic slope stability analysis (Fig. 8), two values of cliff orientation were used; one related to the lower part (Fig. 8a, b, c) and the other to the upper part (Fig. 8 d, e, f) of the slope. The results indicate the possibility of planar sliding along the SL3 and SL2 in the upper part and along SL2 in the lower part. A toppling mechanism is indicated along SL1 in the upper part of the slope. The higher probability of wedge failure is indicated for the rock wedge involving joint set intersections between sets SL1 and SL2.
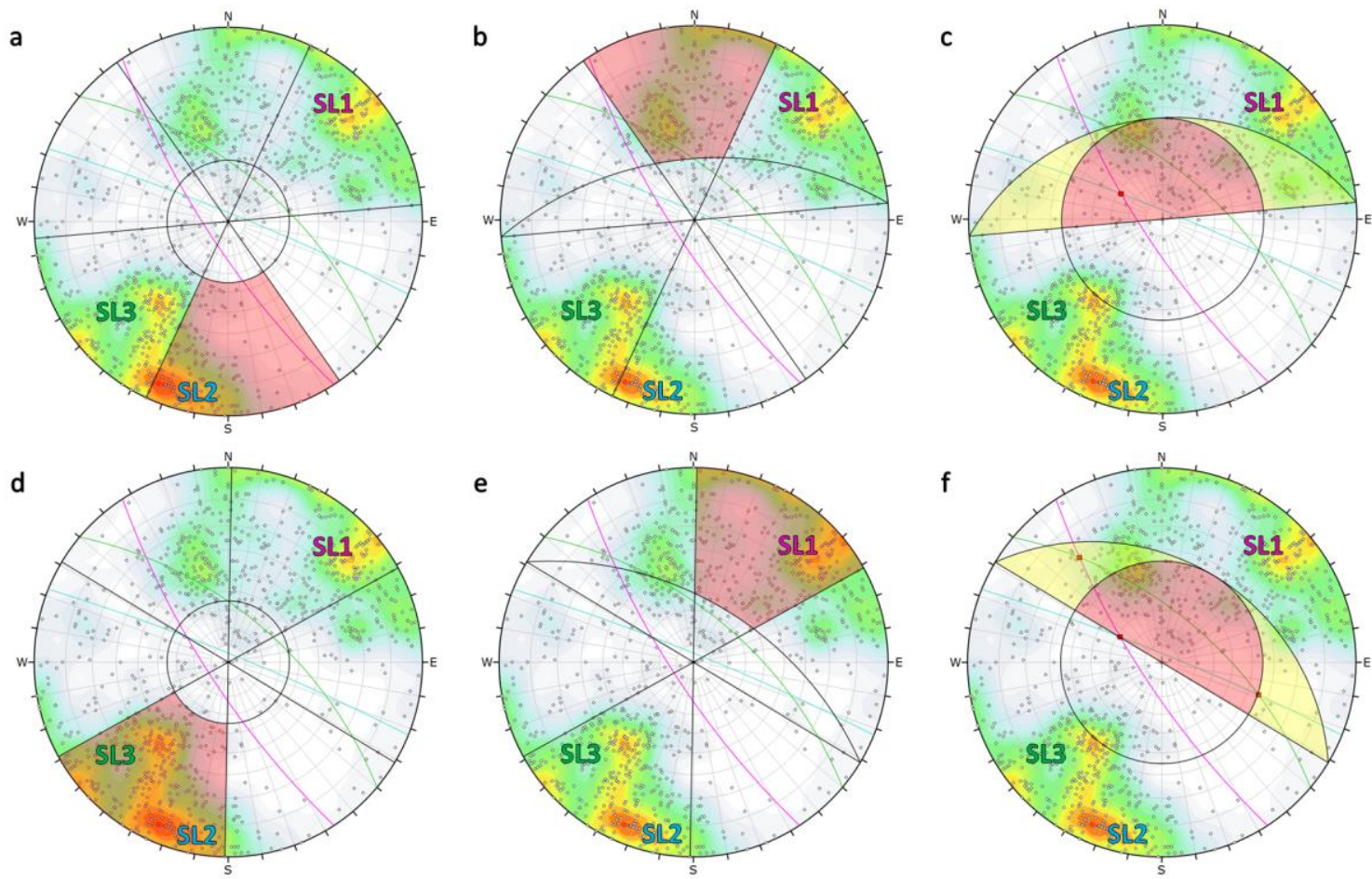

Fig. 8 Kinematic analysis assuming the joint sets derived from the TLS point clouds: a) planar sliding on the lower part of the cliff, b) toppling on the lower part of the cliff, c) wedge sliding on the lower part of the cliff, d) planar sliding on the higher part of the cliff, e) toppling on the higher part of the cliff, f) wedge sliding on the higher part of the cliff. The red areas include the critical planes

It should be noted that a fourth set (around $165^{\circ} / 56^{\circ}$ ) is visible in Fig. 8. The measurements related to this set were obtained mainly in the lower parts of the cliff, where the slope face has a similar dip direction. Due to this, the measurements associated with this discontinuity set were interpreted as part of the slope faces and not as discontinuities. Moreover, this set was not recognized during the engineering geological surveys. For these reasons it was decided not to consider it in the kinematic and numerical analyses.

The digitization of the blocks in the landslide deposit area allowed an evaluation of the block size distribution. More than 300 blocks were mapped, corresponding to almost the $37 \%$ of the estimated deposit volume. The majority of larger blocks broke only on impact with the ground (Fig. 9). 


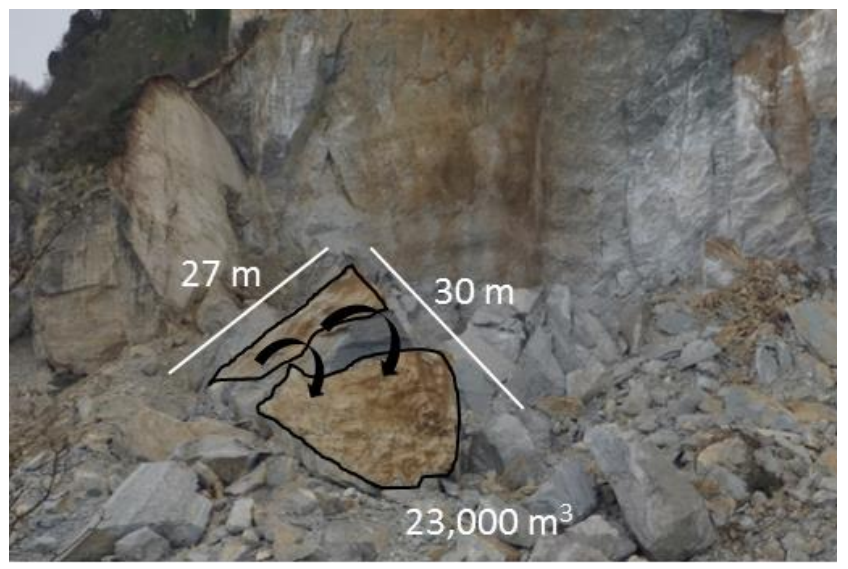

Fig. 9 Blocks in the deposit area, which appear to have been broken on impact with the ground

A block volume distribution diagram was used to summarize the results (Fig. 10). The graph in Fig. 11 is related to the measured length of the block sides. An average length was calculated from the three measures extracted for each block. From this analysis, $48 \%$ of the blocks have an average side longer than $4 \mathrm{~m}$ and the $33 \%$ longer than $5 \mathrm{~m}$. Considering the possible rock fragmentation of the blocks during the free fall phase, the minimum joint spacing in the numerical model was assumed to be equal to $5 \mathrm{~m}$ for the discontinuities belonging to the set SL1 and SL3. The joint set SL2 shows an average spacing larger than the SL1 and SL3 in the geomechanical field-surveys results. To maintain the same proportion (about $4 \mathrm{x}$ ) a spacing of $20 \mathrm{~m}$ was assumed for the joints belonging to this set. This is in accordance with the geomechanical survey conducted on the top of the slab after the 2014 event, which showed a mean spacing of 20-22 m between the discontinuities belonging to the SL3 set (Enser, 2014).
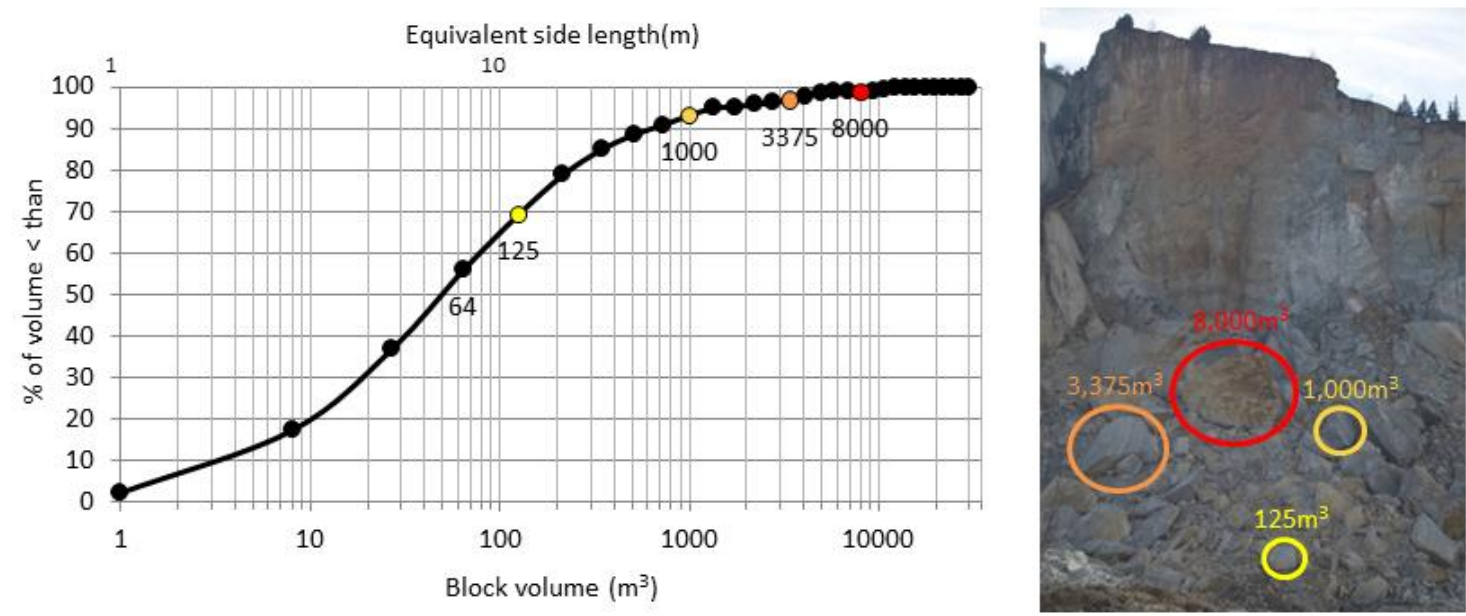

Fig. 10 Block size distribution with examples of the block dimensions in the deposit area

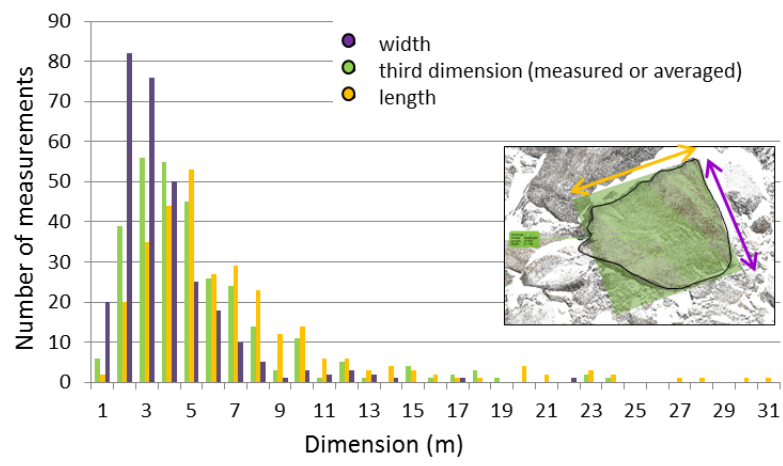

Fig. 11 Distribution of the block dimensions 
The comparison of multi-temporal TLS scans allows delineation of the area affected by the 2014 failure. The differences are measured on a $50 \mathrm{~m}$ scale. As shown in Fig. 12, the maximum difference between the two surfaces (purple area) is located in the lower eastern part of the area, close to the section 3. The accumulation area can be seen in the lower part, showing positive values. Examining section 3, the discontinuity belonging to the set SL2 is clearly recognizable at the top.

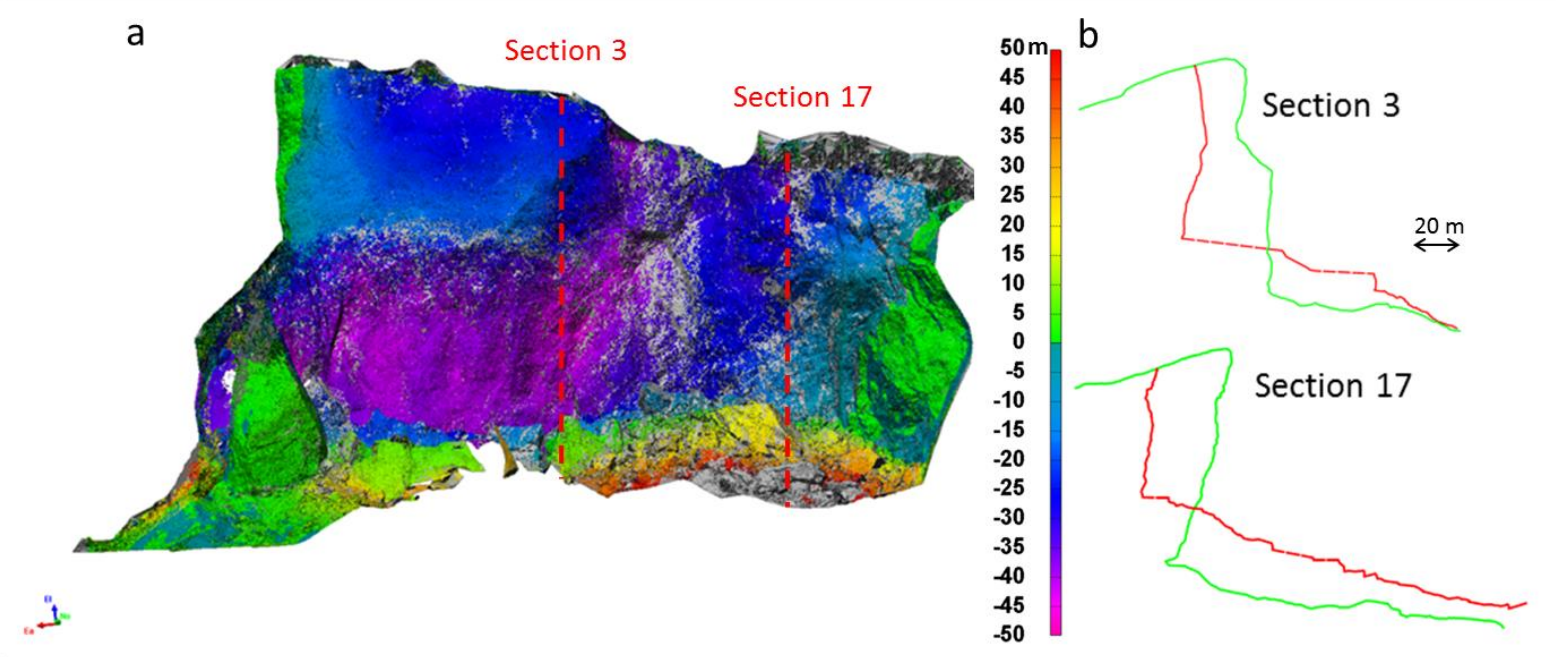

Fig. 12 a) Difference between the 2 surfaces, projected on the post-failure surface, in blue and purple the areas influenced by the movement, in red and yellow the accumulation areas; b) sections from the pre- (green) and post-failure (red) TLS point clouds

\subsection{Distinct Element Analysis}

The model results were evaluated by comparison with the data from the TLS multi-temporal analysis (Fig 13a). As stated above, the 3DEC model was initially run to equilibrium. Results of this phase are visible in Fig. 13b, where the dotted white line indicates the extent of the detachment area derived from the multi-temporal analysis on the TLS point clouds. Displacements are mostly registered in the upper part of the slope, in an area similar to the one effectively involved in the 2014 failure. After the equilibrium state was reached, two further simulations were performed. The first simulation investigated the influence of a decrease in the joint cohesion. Results show only local movements in the upper part of the area affected by the landslide (Fig. 13c). The maximum displacements are in the order of $1 \mathrm{~mm}$. Comparing the results with the detachment area estimated from the TLS, it is clear that a decrease in the joint strength properties alone does not lead to a failure similar to the one occurred in February 2014. Displacements derived from this simulation appear to be more similar to localized rock falls and the rock mass volume is much lower than the one observed in the field. Thus, other predisposing and/or triggering factors need to be investigated. For this reason, a second simulation was performed, including the undermining at the base of the cliff. Results for different calculations cycles are shown in in Fig. 13d, 14 and 15. The model did not reach equilibrium after the undermining. The area with the maximum displacements is very similar to that affected by failure. Examining the section in Fig. 14, showing the displacements after 50,000 cycles, it appears that the upper part of the cliff is characterized by larger displacements when compared to the lower slope. The largest displacements are shown on the joint SL2.1. Along the nearest discontinuity belonging to the SL2, lower displacement rates are apparent. Due to the undermining, some blocks in the lower part of the rock mass detached from the cliff (Fig. 15). Examining the results, it is clear that, in all the cases, the main displacements are related to the joint SL2.1. The position of the joint sets in 3DEC is defined assigning a point of origin. As can be seen in the section (Fig. 14), due to the large spacing of the SL2 discontinuity set (20 m) the definition of the point could play an important role in the mechanism and also in the volume of the failure. To account for this, in the 3DEC simulations the position of joint SL2.1 0was inserted deterministically.

It should be emphasised that the failure mechanism shown in the 3DEC model is slightly different from the one visible in multi-temporal analysis (Fig 12b). It is in fact clear (Figure 12b) that the failure started along SL2.1, then propagated partly along other pre-existing discontinuities and partly through the intact rock mass. Due to the inability to simulate the formation of new factures in 3DEC, the numerical simulation also show displacements concentrated along the SL2 in the lower slope area. 

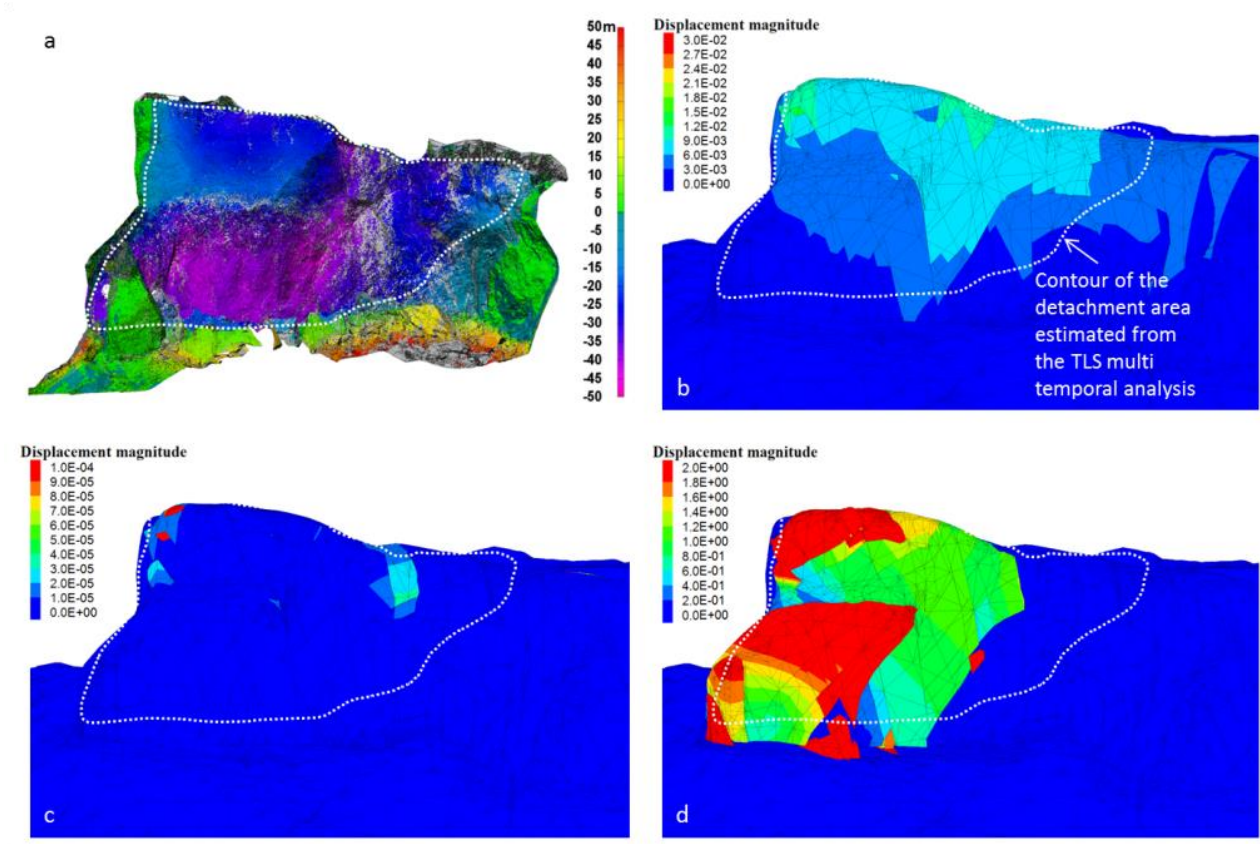

Fig. 13 3DEC results, comparing model simulations and multi-temporal TLS scans. a) The dotted white line indicates the contour of the detachment area derived from TLS point clouds; it is reported on the numerical model results for comparison. b) Results of the first phase of the 3DEC simulation in which the equilibrium was reached; c) results of the simulation performed by lowering the joint strength parameters; d) results of the simulation performed after simulating the undermined area (130,000 cycles). Displacement magnitude is expressed in metres.

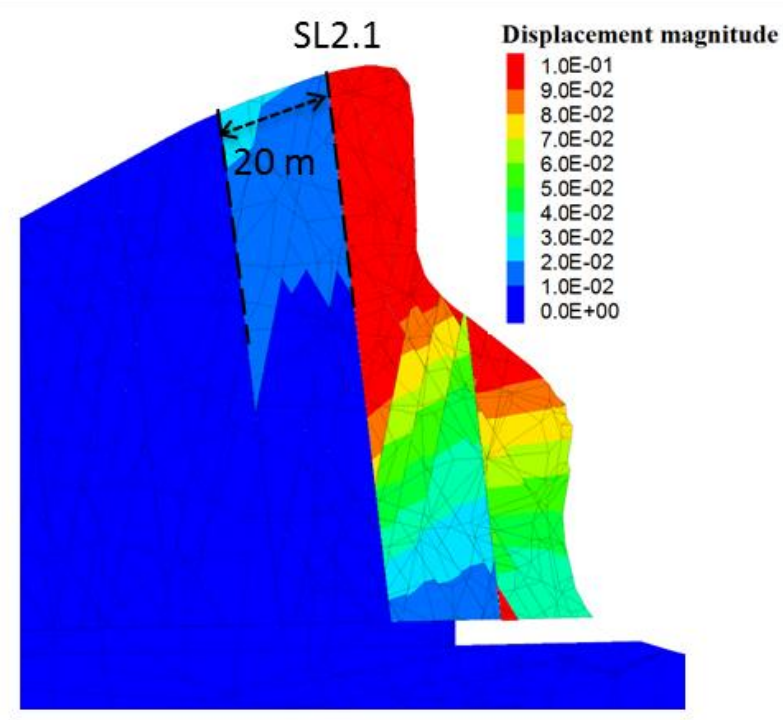

Fig. 14 Displacements on a 2D section extracted from the 3DEC simulation including the undermined area at 50,000 cycles. Displacement magnitude is expressed in metres. 

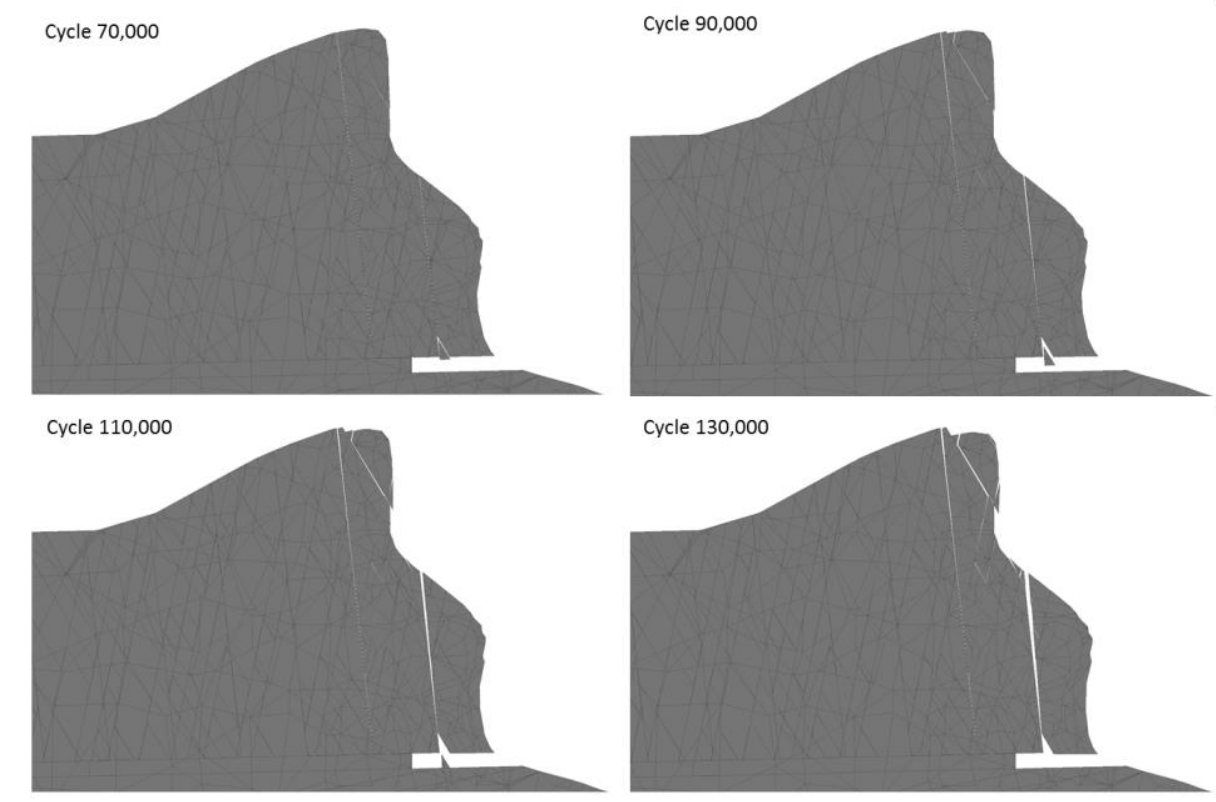

Fig. 15 Evolution of the displacements on a 2D section extracted from the 3DEC simulation including the undermined area.

\section{Discussion}

The dataset provided by the TLS measurements allowed an improved understanding of the 2014 slope failure mechanism affecting the north-eastern side of the San Leo rock slab. The TLS contribution was critical in discontinuity mapping, due to the difficulties related to the traditional investigations of sub-vertical unstable rock cliffs. The traditional field surveys allowed estimation of the geomechanical properties of the rock mass. Only a small number of scanlines could be performed; for this reason the reliability of the data obtained from this survey was checked using data from the literature. Some structural features, such as the bedding planes, were not recognized using traditional methods alone. A combination of the two methods allowed the estimation of the geometrical and mechanical properties required as input in the 3D Distinct Element Method simulations. Pre- and post-failure surfaces were derived and compared to estimate the detachment area. Measurements of the block sizes in the deposit area were used to infer an effective equivalent spacing for the three recognized joint sets. In geological problems many orders of magnitude of fractures can be frequently observed, but not all discontinuities can or should be practically considered in the modelling phase (Dershowitz, 2014). Moreover, when complex or extended geometries are used for numerical modelling, an increase in the joint spacing is required, to allow reasonable simulation times (Wang et al. 2012; Francioni et al. 2014). The procedure described can be applied in similar cases to allow an assessment of a meaningful joint spacing.

The Distinct Element model shows promising results and provides a further understanding of the role of the discontinuities and of the undermining of the slab in slope failure mechanisms. Based on field evidence and on the results of the model simulations, joint set SL2 seems to be a critical factor in promoting slope instability. Consequently, a deterministic approach was used to input this joint set into the model, avoiding possible errors related to the use of random origin points. In addition, this joint set was characterized by a higher value of persistence. Based on kinematic analysis, this joint set was indicated as a potential plane along which sliding can occur. At the same time, from the photos taken before the 2014 failure, the presence of an undermined sector of the slope in the analysed area was clearly recognizable. Due to the almost-vertical orientation of SL2 joint set, and the undermining at the toe of the slope, the movement, even though having a sliding component, was probably developing as a secondary toppling mechanism, as described in Evans (1981). The model results and the multi-temporal analysis suggest the following interpretation of the 2014 landslide:

- the cliff became unstable due to the progressive undermining of the rock slab;

- the movements started, or accelerated, along the pre-existing SL2.1 discontinuity, and probably propagated partly along other pre-existing discontinuities and partly through the intact rock mass, with the failure of intact rock bridges. In fact, the comparison between the measured $\mathrm{P}_{21}$ before and after the failure shows a small increase, indicating the creation of new fractures during the failure.

These hypotheses are in agreement with the landslide reconstruction proposed in Borgatti et al. (2015). Therefore, the landslide displayed a complex style of activity, and can be described as a rock slide-rock topple. 
As stated before, discontinuities belonging to the SL2 joint set were mapped at the top of the slab. Not only joint SL2.1, but also the other joints having a similar orientation, located towards the inner part of the slab showed displacements in the simulations, indicating a progressive increase in their aperture. The slope failure may lead to the development of tension cracks and dilation of joints predisposing the slope to further instability of the same type.

Comparing the results of the simulations, the importance of the undermining of the rock slab in the 2014 landslide is evident. Without inserting the undermined area, the model-displacements are concentrated only in small areas in the upper part of the slope and a low rate of displacement is reached. In contrast, when the undermining is considered, almost the entire area affected by the landslide displays higher movement rates. It is important to note that in other parts of the slab, rock detachments (mostly wedge failures along at least two preexisting joint sets), especially in the lower part of the cliff, were observed in the field in areas where no erosional features have developed yet; as a matter of fact, they are always associated with the presence of a weathered clay-shale layer. The degradation of the clay-shale properties may act as predisposing factor in the evolution of slope instability processes. More investigations are needed regarding this possible behaviour. Further studies are also required to evaluate the extent of undermining beneath the slab, which could only be estimated in the present work. Moreover, new monitoring data (spring discharges and groundwater levels) will be used to calibrate the hydrogeological model (Spreafico et al. 2015 a) providing piezometric levels to be used in slope stability models.

Due to the limitations of the performed simulations, i.e. the blocks were rigid and no new fractures could develop through intact rock, it was not possible to fully reproduce the landslide mechanisms. The dominant roles of joint set SL2 and undermining of the rock slab were however clearly demonstrated. Further analyses, involving the consideration of brittle fracturing, are suggested. Using hybrid finite/discrete element codes it is possible to simulate the development of new fractures in intact rock (Stead et al. 2006) and such an analysis might be important in the simulation of San Leo slope instability processes. Due to the importance of the discontinuity networks, future developments should also include the application of a Discrete Fracture Network (DFN) procedure, to allow a more realistic representation of the joint network (Elmo and Stead 2010). Input data for the DFN construction are already available through the TLS fracture mapping. Several authors (Elmo 2006; Sturzenegger et al. 2011) have shown how data achieved from terrestrial remote sensing techniques, including both photogrammetry and laser scanner, combined with traditional scanline surveys, can be used for the generation of a DFN, using a statistical approach. The use of these DFN models, combined with the deterministic definition of the main joints involved in the failure, i.e. the joint SL2.1, may lead to a more efficient approach for the discontinuities definition in the numerical models.

\section{Conclusions}

A multi-disciplinary approach involving Terrestrial Laser Scanning and 3D Distinct Element modelling is proposed in order to back-analyse the 2014 San Leo landslide.

The capability of the TLS to fully describe the geometrical properties of the rock mass was demonstrated, from the creation of the initial geometry model and the extraction of the discontinuities characteristics through to the validation of the 3DEC simulation results. On the basis of the numerical simulations, the role of the discontinuity sets was discussed. Results emphasized the importance of the sub-vertical joints, striking almost parallel to the cliff orientation, in the failure development. These analyses highlighted the importance of the erosion of the clay-shale substratum in promoting the rock slab instability. In particular, the undermining of the slab was indicated as a predisposing factor for the onset of large-scale rapid slope instability processes.

The model results allow an improved insight on collateral slope instability processes occurring at the edge of rock slabs, in the wider context of the lateral spreading phenomena, which affect San Leo and many other similar rock plateaux in the northern Apennines.

\section{Acknowledgements}

The authors wish to thank two anonymous reviewers and Dr. Loren Lorig (ITASCA) for his advices on numerical modelling.

\section{References}

Abellan A, Vilaplana J M, Calvet J, Garcia-Selles D, Asensio E (2011) Rockfall monitoring by Terrestrial Laser Scanning - case study of the basaltic rock face at Castellfollit de la Roca (Catalonia, Spain). Nat. Hazards Earth Syst. Sci., 11: 829-841

Barton N R, Lien R, Lunde J (1974) Engineering classification of rock masses for the design of tunnel support. Rock Mech. 6, 4: 189-239 
Barton N R, Choubey V (1977) The shear strength of rock joints in theory and practice. Rock Mech., 10(1-2):154

Benedetti G, Bernardi M, Bonaga G, Borgatti L, Continelli F, Ghirotti M, Guerra C, Landuzzi A, Lucente C C, Marchi G (2013) San Leo: centuries of coexistence with landslides. Landslide Science and Practice, 6: 529 537

Borgatti L, Guerra C, Nesci O, Romeo R W, Veneri F, Benedetti G, Landuzzi A, Marchi G Lucente C C (2015) The 27th February 2014 San Leo rock fall (northern Italy). Landslides, 12 (2): 387-394

Bozzano F, Bretschneider A, Martino S (2008) - Stress-strain history from the geological evolution of the Orvieto and Radicofani cliff slopes (Italy). Landslides, 5 (4): 351-366

Bozzano F, Bretschneider A, Esposito C, Martino S, Prestininzi A (2013) Lateral spreading processes in mountain ranges: Insights from an analogue modelling experiment. Tectonophysics, 605 (11): 88-95

Brideau M A, Stead D (2010) Controls on Block Toppling Using a Three-Dimensional Distinct Element Approach, Rock Mechanics and Rock Engineering, Rock Mech. Rock Eng., 43:241-260

Brideau M A, Pedrazzini A, Stead D, Jaboyedoff M, Froese C, van Zeyl D (2011) Three-dimensional slope stability analysis of South Peak, Alberta, Canada. Landslides, 8, 2: 139-158

Brideau M A, Stead D (2011) The influence of three-dimensional kinematic controls on rock slope stability. Proceedings of the 2nd International FLAC/DEM Symposium, February 14-16, Melbourne, Australia

Brideau M A, Stead D (2012) Evaluating kinematic controls on planar translational slope failure mechanisms using three-dimensional distinct element modelling. Geotech. Geol. Eng., 30, 4: 991-1011

Cornamusini G, Martelli L, Conti P, Pieruccini P, Benini A, Bonciani F, Callegari I, Carmignani L (2013) Note Illustrative della Carta Geologica d'Italia alla scala 1:50.000, foglio 266 "Mercato Saraceno". Servizio Geologico d'Italia-Regione Emilia Romagna

Casagli N (1994) Fenomeni di instabilità in ammassi rocciosi sovrastanti un substrato deformabile: analisi di alcuni esempi nell'Appennino settentrionale. II Convegno Nazionale dei Giovani ricercatori di Geologia Applicata, Viterbo

Cervi F, Corsini A, Doveri M, Mussi M, Ronchetti F, Tazioli A (2014) Characterizing the recharge of fractured aquifers: a case study in a flysch rock mass of the northern Apennines (Italy). Engineering Geology for Society and Territory, 3: 563-567

Conti S, Tosatti G (1996) Tectonic vs gravitational processes affecting Ligurian and Epiligurian units in the Marecchia valley (Northern Apennines). Memorie di Scienze Geologiche, 48: 107-142

Crosta G (2006) Landslide, spreading, deep-seated gravitational deformation: analysis, examples, problems and proposals. Geografia Fisica e Dinamica Quaternaria, 19 (2): 297-313

D’Ambra S, Giglio G, Lembo-Fazio A (2004) Interventi di sistemazione e stabilizzazione della Rupe di San Leo. $10^{\circ}$ Congress INTERPRAEVENT 2004, Riva del Garda

Deere D U, Miller R P (1966) Engineering classification and index properties of rock. Technical Report No. AFNL-TR-65-116. Albuquerque, Air Force Weapons Laboratory

Dershowitz, W, Lee G, Geier J, Foxford T, La Pointe P, Thomas A (1998) FracMan-Interactive discrete fracture data analysis, geometric modeling, and exploration simulation, version 2.6, users guide, $189 \mathrm{pp}$., Golder Assoc. Inc., Denver, Colorado

Dershowitz B. (2014) Truth and Beauty - Which fractures really matter? Keynote presentation at DFNE Conference, October 19-22 2014, Vancouver, Canada

Dramis F, Sorriso-Valvo M (1994) Deep-seated gravitational slope deformations, related landslides and 
tectonics. Engineering Geology, 38:231-243

Elmo D, Stead D (2010) An integrated numerical modelling-discrete fracture network approach applied to the characterisation of rock mass strength of naturally fractured pillars. Rock Mech. Rock Eng., 43: 3-19

Enser srl (2014) Technical report

Evans R S (1981) An analysis of secondary toppling rock failures - the stress redistribution method. J. Eng. Geol., The Geological Society, 77-86

Fekete S, Diederichs M (2013) Integration of three-dimensional laser scanning with discontinuum modelling for stability analysis of tunnels in blocky rockmasses. International Journal of Rock Mechanics and Mining Sciences, 57: 11-23

Firpo G, Salvini R, Francioni M, Ranjith P G (2011) Use of Digital Terrestrial Photogrammetry in rocky slope stability analysis by Distinct Element Numerical Methods. Int. J. Rock Mech. Min., 48, 7: 1045-1054

Fondedile Italsonda (1972) Technical report

Francioni M, Salvini R, Stead D, Litrico S (2014): A case study integrating remote sensing and distinct element analysis to quarry slope stability assessment in the Monte Altissimo area, Italy. Engineering Geology. http://dx.doi.org/10.1016/j.enggeo.2014.09.003

Geoemme (2001) Technical report

Girardeau-Montaut D (2014), CloudCompare (http://www.danielgm.net/cc/)

Hoek E, Bray J W (1981) Rock Slope Engineering, 3rd ed. Instituteof Mining and Metallurgy, London

InnovMetric Software(2014) - Polyworks version 2014, Quebec City, Canada (http://www.innovmetric.com/)

International Society of Rock Mechanics (ISRM) (1978) Suggested Methods for Quantitative Description of Discontinuties in Rock Masses. International Journal of Rock Mechanics and Mining Sciences, 15: 319-368.

ItascaTM $^{\mathrm{TM}}$ 2014, 3DEC version 5.00.178, Kubrix version 14. Itasca Consulting Group Inc., Minneapolis, Minnesota (2008) (http://www.itascacg.com)

Kalenchuk K S, Hutchinson D J, Diederichs M S, Barla G, Barla M, Piovano G (2010) Three-dimensional mixed continuum-discontinuum numerical simulation of the Beauregard Landslide. Proceedings of Eurock 2010, Lausanne

Kuhn D, Prüfer S (2014) Coastal cliff monitoring and analysis of mass wasting processes with the application of terrestrial laser scanning: A case study of Rügen, Germany. Geomorphology, 213: 153-165

Mantovani M, Devoto S, Forte E, Mocnik A, Pasuto A, Piacentini D, Soldati M (2013) A multidisciplinary approach for rock spreading and block sliding investigation in the north-western coast of Malta. Landslides, 10: 611-622

Martinotti G, Giordan G, Giardino M, Ratto S (2011) Controlling factors for deep-seated gravitational slope deformation (DSGSD) in the Aosta Valley (NW Alps, Italy). Geological Society, London, Special Publications, 351: 113-131

Mauldon M, Dunne W M, Rohrbaugh M B Jr (2001) Circular scanlines and circular windows: new tools for characterizing the geometry of fracture traces. Journal of Structural Geology, 23: 247-258

McNeel and Associates (2014) Rhinoceros 4, SR9 http://www.rhino3d.com/download/rhino/4.0 (accessed 01.06.2014)

Pasuto A, Soldati M (2013) Lateral Spreading. Treatise on Geomorphology, 7.25: 239-248 
Pesci A, Fabris M, Conforti D, Loddo F, Baldi P, Anzidei M (2007) Integration of ground-based laser scanner and aerial digital photogrammetry for topographic modelling of Vesuvio volcano. Journal of Volcanology and Geothermal Research, 162, 3-4: 123-138

Ribacchi R, Tommasi P (1988) Preservation and protection of the historical town of S. Leo (Italy). Proc. Int. Symp. Eng. Geology- Study, Preservation and Protection of Ancient Works, Monuments and Historical Sites, $55-64$

Shugar D H, Clague J J (2011) The sedimentology and geomorphology of rock avalanche deposits on glaciers, Sedimentology, 58 (7): 1762-1783

Soldati M (2013) Deep-seated gravitational slope deformation. In: Encyclopedia of Natural Hazards, Springer Netherlands, pp $151-155$

Spreafico M C, Cervi F, Petronici F, Borgatti L (2015 a) Modelling groundwater and slope processes in a calcarenitic slab: the case of San Leo (northern Apennines). Rendiconti Online della Società Geologica Italiana, $34: 23-27$

Spreafico M C, Bacenetti M, Bitelli G, Cervi F, Girelli V A, Lucente C C, Mandanici E, Perotti L, Tini M A, Borgatti L (2015 b) Terrestrial remote sensing techniques for the preservation of cultural heritage sites exposed to landslide hazard: the San Leo rock slab (Italy). European Journal of Remote Sensing, submitted.

Spreafico M C, Girelli V A, Lucente C C, Tini M A, Bitelli G, Borgatti L (2014) Terrestrial laser scanner point clouds for landslide hazard assessment in the cliff of San Leo (northern Apennines, Italy). $9^{\circ}$ Convegno Nazionale del Gruppo di Geologia Informatica, Montefalco (PG)

Stead D, Eberhardt E, Coggan J C (2006) Developments in the characterization of complex rock slope deformations and failure using numerical modelling techniques. Engineering Geology, 83: 217-235.

Sturzenegger M, Stead D (2009a) Close-range terrestrial digital photogrammetry and terrestrial laser scanning for discontinuity characterization on rock cuts. Engineering Geology, 106 (1):163-182.

Sturzenegger M, Stead, D (2009b) Quantifying discontinuity orientation and persistence on high mountain rock slopes and large landslides using terrestrial remote sensing techniques. Special Issue: Natural Hazards and Earth Systems Science, 9:267-287

Sturzenegger M, Stead D, Elmo D (2011) Terrestrial remote sensing-based estimation of discontinuity frequency, mean trace length, block size/shape and dependence on observation scale. Engineering Geology, 119(3-4): 96-111.

Varnes D J (1978) Slope movement types and processes. In: Special Report 176: Landslides: Analysis and Control, Eds. Schuster R. L, Krizek R J. Transportation and Road Research Board, National Academy of Science, Washington D. C.: 11-33

Viero A, Teza G, Massironi M, Jaboyedoff M, Galgaro A (2010) Laser scanning-based recognition of rotational movements on a deep seated gravitational instability: The Cinque Torri case (North-Eastern Italian Alps). Geomorphology, 122, 1-2: 191-204

Yeung M R, Wong K L (2007) Three-dimensional kinematic conditions for toppling. Proceedings of the $1^{\text {st }}$ Canada-US Rock Mechanics Symposium, 27-31 May 2007, Vancouver, Canada

Wang X, Kulatilake P H S W, Song W (2012) Stability investigations around a mine tunnel through threedimensional discontinuum and continuum stress analyses. Tunnelling and Underground Space Technology, 32: 98-112 